\title{
A bridging assay for detection and characterization of anti-drug antibodies to dostarlimab, a new anti-PD-1 therapeutic monoclonal antibody
}

\author{
Marilyn Patterson ${ }^{1}$, Lee Anne Beausang ${ }^{2}$, Bonita Rup ${ }^{3}$, Ronald R. Bowsher ${ }^{4}$, Kim Krug $^{5}$, Murad Melhem ${ }^{6}$ and \\ Sharon Lu $6^{6^{*}}$
}

\begin{abstract}
Dostarlimab (JEMPERLI) is a humanized anti-programmed death 1 (PD-1) immunoglobulin (lg)G4-kappa monoclonal antibody that binds to the PD-1 receptor and competitively inhibits binding of its ligands, PD-L1 and PD-L2. Dostarlimab was recently approved in the USA and the European Union. Because dostarlimab is a macromolecular therapeutic, it has the potential to elicit the formation of anti-drug antibodies, which have the capability to impact the drug's safety and efficacy and to alter pharmacokinetics. The immunogenic potential of dostarlimab remains unknown, and it was therefore necessary to develop analytical assays to detect and characterize anti-drug antibodies as a key component in the mitigation of immunogenicity risk. Here, we present the development and optimization of a 3-tiered electrochemiluminescense bridging assay for the investigation of dostarlimab clinical immunogenicity. In this work, the full details of the method, statistical data analysis and cut point determinations, assay performance during clinical sample analysis, and associated regulatory expectations are discussed. The full validation of this 3-tier anti-drug antibody assay enabled dostarlimab immunogenicity evaluation in clinical studies. Trial registration: Clinicaltrials.gov, NCT02715284. Registered 9 March 2016
\end{abstract}

Keywords: 3-tier ADA assay, Bridging assay, Check point inhibitor, Dostarlimab, immunogenicity

\section{Introduction}

Dostarlimab (JEMPERLI) is a humanized anti-programmed death 1 (PD-1) immunoglobulin (Ig)G4-kappa monoclonal antibody (mAb) that competitively inhibits the PD-1 receptor by blocking binding of its ligands (PDL1 and PD-L2) (Oaknin et al. 2020). In the USA, dostarlimab was recently approved as a monotherapy in adult patients with mismatch repair-deficient (dMMR) recurrent or advanced endometrial cancer that has progressed

\footnotetext{
${ }^{*}$ Correspondence: Slu@scholarrock.com

${ }^{6}$ Clinical Pharmacology, Oncology, GlaxoSmithKline, 1000 Winter St, Waltham, MA 02451, USA

Full list of author information is available at the end of the article Sharon Lu is employed by GlaxoSmithKline when the research was conducted.
}

on or after a platinum-containing regimen (US Food and Drug Administration 2021). In the European Union, dostarlimab was recently approved as a monotherapy in adult patients with recurrent or advanced dMMR/ microsatellite instability-high endometrial cancer that has progressed on or after treatment with a platinumcontaining regimen (European Medicines Agency 2021). As with other antibodies, anti-drug antibodies (ADAs) may be detectable after the administration of dostarlimab (Pineda et al. 2016).

ADAs may interfere with therapeutic antibodies, leading to a reduction in efficacy and/or an altered pharmacokinetic (PK) profile, and have the potential to trigger adverse immune-mediated events that can be as serious as anaphylaxis (Bloem et al. 2017; Garcês and Demengeot 
2018). However, it is currently impossible to predict the impact of the immunogenicity of dostarlimab prior to experience in the clinic. Therefore, it is necessary to develop analytical assays to evaluate the potential clinical impact of ADAs (Pineda et al. 2016). Today, several different analytical design options exist for the detection of ADAs to mAb therapeutics. Of these, the most frequently used detection strategies are conventional enzyme-linked immunosorbent assays (ELISA) and immunoassays using electrochemiluminescence (ECLIA) detection. Such assays can be performed using direct, indirect, and bridge formats (Pineda et al. 2016). The ELISA format has been associated with higher rates of false-positives, high background noise, and poor detection of low-affinity ADAs (Pineda et al. 2016; Wadhwa et al. 2015). In contrast, the electrochemiluminescense (ECL) platform is associated with low background noise and increased sensitivity with multiple orders of dynamic range, thus increasing the assay throughput and providing for the possibility of detection of low-affinity ADAs (Wadhwa et al. 2015).

A multitiered approach (screening, confirmatory, and titer) for the identification and characterization of ADAs is the standard testing paradigm used today, and it is recommended by regulatory agencies (Jaki et al. 2016). In addition, bioassays or ligand binding assays can be used to identify neutralizing Abs.

The United States Food and Drug Administration (FDA) recommends that screening assays be designed to deliver a false-positive rate of $5 \%$ to decrease the possibility of false-negatives (Jaki et al. 2016; Jani et al. 2015). Therefore, to remove most false-positives that passed the screening assay, confirmatory assays are designed to reduce false-positive results to a $1 \%$ rate. Appropriate and stringent positivity cut points (screening, confirmatory, and titer) must be established for each tier of the process.

Here, we present the development and optimization of a 3-tiered ECL bridging assay for the detection, confirmation, and titer assessment of ADAs against dostarlimab. In this work, full details of the method, statistical data analysis and cut point determinations, assay performance during clinical sample analysis, and associated regulatory expectations are discussed. The full validation of this 3-tier ADA assay enabled evaluation of dostarlimab immunogenicity in clinical studies.

\section{Materials and methods \\ Materials \\ Critical reagents}

A negative control (NC) containing 10 pooled lots of normal human serum (NHS; BioIVT, Westbury, NY) was used throughout the study. Two positive controls (PCs) were used for method validation. The first control was a dostarlimab-affinity purified anti-idiotypic polyclonal rabbit anti-dostarlimab PC antibody (pAb; AnaptysBio, San Diego, CA). The second control was a mouse mAb generated from clone \#6G10 (Precision Antibodies, Columbia, MD). Both the pAb and mAb were evaluated in selectivity, sensitivity, and drug tolerance experiments, and the $\mathrm{pAb}$ was used in all remaining validation experiments described in this paper. Dostarlimab (WuXi, Philadelphia, PA) was obtained at a concentration of $20.7 \mathrm{mg} /$ $\mathrm{mL}$. Biotin-labeled dostarlimab (AnaptysBio) for capturing was produced at a concentration of $3.0 \mathrm{mg} / \mathrm{mL}$, and SULFO-TAG-labeled dostarlimab (Meso Scale Discovery [MSD], Rockville, MD) for detection was obtained at a concentration of $5.0 \mathrm{mg} / \mathrm{mL}$. Gold 96-well streptavidin SECTOR plates in black (MSD) were used for the ECL assays.

\section{Serum selections for determination cut points}

Cut points were estimated using a block design as recommended by Devanarayan et al. and according to recent guidance documents (Devanarayan et al. 2017; European Medicines Agency 2017; US Food and Drug Administration 2019). Fifty-one sera from patients with cancer (BioIVT) with balanced sex, age, and cancer types were selected to establish the screening, confirmation, and titer cut points, with 6 observations per patient serum sample by 2 analysts with 3 runs/analyst. The sera from patients with cancer had not been subject to freeze/thaw cycles. Hyperlipidemic serum (BioIVT) and hemolyzed serum (BioIVT) were used to evaluate matrix interference. Both NHS and serum from patients with cancer were used for the selectivity evaluation.

\section{Methods}

\section{Assays}

Positive control (PC) samples prepared in NHS were as follows: pAb low-positive controls (LPCs) 3.45 and 40.0 $\mathrm{ng} / \mathrm{mL}$, mid-positive control (MPC) $500 \mathrm{ng} / \mathrm{mL}$, and high-positive control (HPC) 20,000 ng/mL. The minimum required dilution (MRD) for samples was 4 . Controls and samples were diluted to the MRD using low cross (LC) buffer (Candor, Wangen, Germany).

\section{Tier 1: Screening assay}

Intermediate 1:10 dilutions of both SULFO-TAG-labeled dostarlimab and biotin-tagged dostarlimab with LC buffer were made. The SULFO-TAG-labeled dostarlimab dilution $(22.0 \mu \mathrm{L})$ and the biotin-tagged dostarlimab dilution $(36.7 \mu \mathrm{L})$ were added to $11.0 \mathrm{~mL}$ of $\mathrm{LC}$ buffer to create a master mix (MM). Both samples and pAb PCs (LPC [40.0 ng/mL], MPC, and HPC) were diluted to the MRD with LC buffer. To note, after validation, a second $\mathrm{pAb}$ LPC at a concentration of $3.45 \mathrm{ng} / \mathrm{mL}$ was added to ensure a $1 \%$ false-negative rate for day-to-day sample 
analysis. MM $(200 \mu \mathrm{L})$ was added to each diluted PC and sample tube, which were then incubated at $25^{\circ} \mathrm{C}$ for $3 \mathrm{~h}$ with agitation. With $1 \mathrm{~h}$ left of the 3-h MM incubation, a streptavidin gold plate was removed from the refrigerator and allowed to reach room temperature. The plate was blocked with $150 \mu \mathrm{L}$ of LC buffer per well at $25^{\circ} \mathrm{C}$ for 30 min with agitation, occurring simultaneously with the end of the MM incubation period. The assay plate was then washed 3 times on a plate washer. Next, 50.0 $\mu \mathrm{L}$ of all samples and PCs were added to the plate and incubated for $1 \mathrm{~h}$ at $25^{\circ} \mathrm{C}$ with agitation. The plate was washed 3 times on the plate washer and then the assay was stopped by the addition of $150 \mu \mathrm{L}$ of $2 \mathrm{X}$ read buffer (MSD). The plate was then read using the MESO QuickPlex SQ 120 (MSD).

\section{Tier 2: Confirmatory assay}

Intermediate 1:10 dilutions of both SULFO-TAG-labeled dostarlimab and biotin-tagged dostarlimab were made with LC buffer. The SULFO-TAG-labeled dostarlimab dilution $(22.0 \mu \mathrm{L})$ and the biotin-tagged dostarlimab dilution $(36.7 \mu \mathrm{L})$ were added to $11.0 \mathrm{~mL}$ of $\mathrm{LC}$ buffer to create a MM. In addition, an LC-drug buffer was prepared by diluting dostarlimab $(20.7 \mathrm{mg} / \mathrm{mL})$ to $540 \mu \mathrm{g} / \mathrm{mL}$ in LC buffer. Two sets of pAb PCs (LPC [40 ng/mL], MPC, and HPC) and samples were diluted to the MRD-one set was diluted with LC buffer (unspiked) and the other set was diluted with LC-drug buffer (spiked with unlabeled drug, final dostarlimab concentration $405 \mu \mathrm{g} / \mathrm{mL}$ ). The diluted PCs and samples were then incubated at 25 ${ }^{\circ} \mathrm{C}$ for $1 \mathrm{~h}$ with agitation. MM $(200.0 \mu \mathrm{L})$ was added to each diluted PC and sample tube, which were subsequently incubated at $25^{\circ} \mathrm{C}$ for $3 \mathrm{~h}$ with agitation. At this point, the assay was completed in a manner identical to the screening assay.

\section{Tier 3: Titer assay}

The pAb PCs (LPC [40 ng/mL], MPC, and HPC) were diluted to the MRD with LC buffer for plate controls. Samples and an additional pAb MPC for low-titer samples or HPC for high-titer samples, to serve as the titer control, were diluted to the MRD with LC buffer. The titer control and samples were then prepared in a threefold dilution series $(1: 4,1: 12,1: 36,1: 108,1: 324,1: 972$,
1:2916, and 1:8748 for low-titer samples; 1:972, 1:2916, $1: 8748,1: 26,244,1: 78,372,1: 236,196,1: 708,588$, and 1:2,125,764 for high-titer samples) using assay diluent buffer (25\% NHS; $4.0 \mathrm{~mL}$ NHS + $12.0 \mathrm{~mL}$ LC buffer). MM $(200 \mu \mathrm{L})$ was added to each diluted PC and sample tube, which were then incubated at $25^{\circ} \mathrm{C}$ for $3 \mathrm{~h}$ with agitation. At this point, the assay was completed in a manner identical to the screening assay.

\section{Acid dissociation}

During method development, acid dissociation through acetic acid (AA) was evaluated to improve the drug tolerance. Two acid dissociation experiments were performed using a set of mouse mAb with $\mathrm{PC}$ concentrations at 0 , $78.125,156.25,312.5,625,1250,2500$, and $5000 \mathrm{ng} / \mathrm{mL}$. The first experiment evaluated different acid dissociation incubation times (15 min, $20 \mathrm{~min}$, and $45 \mathrm{~min}$ ) with $300 \mathrm{mM}$ AA compared with no acid dissociation step. The second experiment was conducted to optimize the AA concentration ( $300 \mathrm{mM}, 600 \mathrm{mM}$, and $900 \mathrm{mM}$ ) for acid dissociation. In this second experiment, different AA concentrations were incubated with the drug for $45 \mathrm{~min}$ and were compared.

\section{Cut points and method validation Cut point determination}

Table 1 shows a balanced Latin square design to establish the cut points for screening, confirmatory, and titer assays, through 2 analysts, with 3 runs each. Individual serum samples obtained from the treatment-naive target population were divided into 3 groups of 17 samples for a total of 51 samples. Each group was tested on a single plate by 2 analysts in each of 3 independent assay runs. The plate formats are listed in Table 2. The plates included samples both in the presence $(405 \mu \mathrm{g} / \mathrm{mL}$, highlighted in gray) and absence of unlabeled dostarlimab (in white). The reported value for each test sample was the mean ECL response from duplicate wells on a plate (Table 2). The NCs were tested twice in the front and back of each plate, and the means of the duplicate wells were reported for a total of $72 \mathrm{ECL}$ values. The pAb LPC (40 ng/mL only), MPC, and HPC were tested once on each plate for a total of 18 ECL values for each PC.

Table 1 Balanced Latin square study design

\begin{tabular}{|c|c|c|c|c|c|c|c|}
\hline \multicolumn{4}{|l|}{ Analyst 1} & \multicolumn{4}{|l|}{ Analyst 2} \\
\hline Run 1 & Group A & Group B & Group C & Run 4 & Group C & Group A & Group B \\
\hline Run 2 & Group B & Group C & Group A & Run 5 & Group B & Group C & Group A \\
\hline Run 3 & Group C & Group A & Group B & Run 6 & Group A & Group B & Group C \\
\hline Plate order & 1 & 2 & 3 & Plate order & 1 & 2 & 3 \\
\hline
\end{tabular}


Table 2 Independent single-plate formats for assay runs

\begin{tabular}{|c|c|c|c|c|c|c|c|c|c|c|c|c|}
\hline Group A & 1 & 2 & 3 & 4 & 5 & 6 & 7 & 8 & 9 & 10 & 11 & 1 \\
\hline A & NC & & NC & & Cut point sample 4 & & Cut point sample 8 & & Cut point sample 12 & & Cut point sample 16 & \\
\hline B & NC & & NC & & Cut point sample 4 & & Cut point sample 8 & & Cut point sample 12 & & Cut point sample 16 & \\
\hline C & $\angle P C^{a}$ & & Cut point sample 1 & & Cut point sample 5 & & Cut point sample 9 & & Cut point sample 13 & & Cut point sample 17 & \\
\hline D & $\angle P C^{a}$ & & Cut point sample 1 & & Cut point sample 5 & & Cut point sample 9 & & Cut point sample 13 & & Cut point sample 17 & \\
\hline E & MPC & & Cut point sample 2 & & Cut point sample 6 & & Cut point sample 10 & & Cut point sample 14 & & NC & \\
\hline$F$ & MPC & & Cut point sample 2 & & Cut point sample 6 & & Cut point sample 10 & & Cut point sample 14 & & NC & \\
\hline G & HPC & & Cut point sample 3 & & Cut point sample 7 & & Cut point sample 11 & & Cut point sample 15 & & NC & \\
\hline H & $\mathrm{HPC}$ & & Cut point sample 3 & & Cut point sample 7 & & Cut point sample 11 & & Cut point sample 15 & & NC & \\
\hline Group B & 1 & 2 & 3 & 4 & 5 & 6 & 7 & 8 & 9 & 10 & 11 & 12 \\
\hline A & NC & & NC & & Cut point sample 21 & & Cut point sample 25 & & Cut point sample 29 & & Cut point sample 33 & \\
\hline B & NC & & NC & & Cut point sample 21 & & Cut point sample 25 & & Cut point sample 29 & & Cut point sample 33 & \\
\hline C & $\angle P C^{a}$ & & Cut point sample 18 & & Cut point sample 22 & & Cut point sample 26 & & Cut point sample 30 & & Cut point sample 34 & \\
\hline D & $\angle P C^{a}$ & & Cut point sample 18 & & Cut point sample 22 & & Cut point sample 26 & & Cut point sample 30 & & Cut point sample 34 & \\
\hline E & MPC & & Cut point sample 19 & & Cut point sample 23 & & Cut point sample 27 & & Cut point sample 31 & & NC & \\
\hline $\mathbf{F}$ & MPC & & Cut point sample 19 & & Cut point sample 23 & & Cut point sample 27 & & Cut point sample 31 & & NC & \\
\hline G & HPC & & Cut point sample 20 & & Cut point sample 24 & & Cut point sample 28 & & Cut point sample 32 & & NC & \\
\hline H & $\mathrm{HPC}$ & & Cut point sample 20 & & Cut point sample 24 & & Cut point sample 28 & & Cut point sample 32 & & NC & \\
\hline Group C & 1 & 2 & 3 & 4 & 5 & 6 & 7 & 8 & 9 & 10 & 11 & 12 \\
\hline A & NC & & NC & & Cut point sample 38 & & Cut point sample 42 & & Cut point sample 46 & & Cut point sample 50 & \\
\hline B & NC & & NC & & Cut point sample 38 & & Cut point sample 42 & & Cut point sample 46 & & Cut point sample 50 & \\
\hline C & $\angle P C^{a}$ & & Cut point sample 35 & & Cut point sample 39 & & Cut point sample 43 & & Cut point sample 47 & & Cut point sample 51 & \\
\hline D & $\angle P C^{a}$ & & Cut point sample 35 & & Cut point sample 39 & & Cut point sample 43 & & Cut point sample 47 & & Cut point sample 51 & \\
\hline$E$ & MPC & & Cut point sample 36 & & Cut point sample 40 & & Cut point sample 44 & & Cut point sample 48 & & $\mathrm{NC}$ & \\
\hline $\mathbf{F}$ & MPC & & Cut point sample 36 & & Cut point sample 40 & & Cut point sample 44 & & Cut point sample 48 & & $\mathrm{NC}$ & \\
\hline G & $\mathrm{HPC}$ & & Cut point sample 37 & & Cut point sample 41 & & Cut point sample 45 & & Cut point sample 49 & & NC & \\
\hline H & HPC & & Cut point sample 37 & & Cut point sample 41 & & Cut point sample 45 & & Cut point sample 49 & & NC & \\
\hline
\end{tabular}

${ }^{a}$ LPC concentration is $40 \mathrm{ng} / \mathrm{mL}$; white cell, unspiked sample; gray cell, spiked with $405 \mathrm{ng} / \mathrm{mL}$ unlabeled dostarlimab

All statistical analyses were completed using $\mathrm{R}$ (version 3.2.5). Statistical methods used for the analyses were consistent with procedures recommended by Devanarayan et al. when applied to immunoassay designs described by Mire-Sluis et al. (Devanarayan et al. 2017; Mire-Sluis et al. 2004).

Sources of variation in the log-transformed NC ECL values, the serum signal-to-noise $(\mathrm{S} / \mathrm{N})$ ratio values $(\mathrm{ECL}$ value from each sample/geometric mean of $\mathrm{NC}$ values from the plate after exclusion of $\mathrm{NC}$ analytical outliers), the percent inhibition (\%INH) in the presence of added unlabeled dostarlimab, and the pAb LPC (40 ng/mL) values were investigated using separate linear mixed effects analysis of variance (ANOVA) models. The fixed effects were analyst, plate order, sex $(\mathrm{S} / \mathrm{N}$ ratio and $\% \mathrm{INH})$, and location (NC only) for systemic difference. The significance level for systemic difference in the least square mean response was 0.05 for each fixed effect. The random effects in the model were run-nested within analyst, assay number (NC only), and residual for NC and pAb LPC (40 $\mathrm{ng} / \mathrm{mL}$ ). Random effects were included for sample within group, run within analyst, assay number, and residual for $\mathrm{S} / \mathrm{N}$ ratio and \% INH. The analytical statistical outliers (referring to process differences including testing method variations) were identified as outside of 1.5 times the interquartile range. For $\mathrm{S} / \mathrm{N}$ ratio and \% INH, the identified outliers were removed, and the model was re-fit until no outlying values were detected. The distribution of individual sample best linear unbiased predictor (BLUP) values was then examined to identify samples as "biologic" statistical outliers (referring to sample source differences at patient level) by applying the same criterion of 1.5 times the interquartile range. All values for individual samples identified as biologic outliers were removed, and the statistical analysis was repeated until no further outliers were present. Normality of conditional residual values and sample BLUP values was evaluated by the ShapiroWilk test and consideration of the skewness coefficient as a relative measure of symmetry (Bulmer 1979; Shapiro and Wilk 1965). The skewness coefficient was calculated as a relative measure of symmetry. A skewness coefficient of 0 indicates that the data are perfectly symmetrical. If 
skewness is less than -1 or greater than +1 and then the distribution is highly skewed; if skewness is between -1 and $-1 / 2$ or $+1 / 2$ and +1 and then the distribution is moderately skewed, and if skewness is between $-1 / 2$ and $+1 / 2$ and then the distribution is approximately symmetric. Typically, the parametric cut point estimates are recommended if the normality test is satisfied (i.e., $P>0.05$ ); however, if normality may not be assumed and then the parametric cut point estimate may be used if the distribution is not highly skewed (i.e., if skewness is between -1 and +1 ) (Shapiro and Wilk 1965).

Cut point determination, a parametric method with Tukey's biweight procedure (Mosteller and Tukey 1977), was used to calculate robust estimates of the mean and standard deviation (SD) of all log-transformed ratios (for both screening cut point and titer cut point) and \%INH (for confirmatory cut point). A conservative false-positive rate of $5 \%$, which can minimize the probability of falsenegative results (Mire-Sluis et al. 2004), was used for screening cut point determination. Respective error rate for confirmatory and titer cut point was $1 \%$ and $0.1 \%$. The cut point values were then determined by multiplying the SD value by the respective quantile of the t-distribution and adding the product to the mean value. For determining both screening and titer cut point factor, inverse log transformation was required. The nonparametric 5\% cut point factor (for screening) and 1\% error rate (for confirmatory) were determined by calculation of the empirical 95th for the log-transformed ratio values followed by an inverse log transformation and 99th percentile for \%INH. The sample size to support the 99.9th percentile is at least 1000; thus, the sample set for the titer assay was insufficient for a nonparametric cut point estimate.

An estimate of the false-negative error rate was determined for the pAb LPC $(40 \mathrm{ng} / \mathrm{mL})$ with the assumption that the distribution of log-transformed $\mathrm{S} / \mathrm{N}$ values is approximately normal. The false-negative error rate, defined as the probability of observing a $\mathrm{S} / \mathrm{N}$ ratio less than the screening cut point factor in a known positive sample, was calculated based on the mean and SD of all log-transformed pAb LPC (40 ng/mL) S/N values and a $\mathrm{t}$-distribution with degrees of freedom equal to the number of ratio values minus 1 .

\section{Method validation and application}

Assay validation was conducted according to the white paper by Shankar et al. and recent guidance documents (European Medicines Agency 2017; Shankar et al. 2008; US Food and Drug Administration 2019). Intra-assay precision was assessed for 5 sets of pAb PCs (LPC [ 40 $\mathrm{ng} / \mathrm{mL}], \mathrm{MPC}$, and HPC), each tested in duplicated wells for a total of 10 wells in a single run. Inter-assay precision was assessed for all observations of each PC sample across all 18 runs. PCs were run once on each plate for a total of 18 values at each PC level. Inter-assay precision was assessed for all observations of each NC sample across all runs. NCs were run 4 times on each plate for a total of 72 values. Acceptance criteria were set at $\leq 20 \%$ for both intra- and inter-assay precisions of all PCs and NCs.

Hook effect was evaluated for the range of $313 \mathrm{ng} / \mathrm{mL}$ to $40,000 \mathrm{ng} / \mathrm{mL}$. Acceptance criteria were the increase in ECL values with increasing concentrations and/or plateau at the highest level.

Selectivity was assessed using 10 NHS samples and 10 cancer sera samples for recovery of spiked rabbit pAb at $40.0 \mathrm{ng} / \mathrm{mL}$ and $20,000 \mathrm{ng} / \mathrm{mL}$ in a single batch. In addition, selectivity was assessed using 10 NHS samples and 10 cancer sera samples for recovery of spiked mouse $\mathrm{mAb}$ at $40.0 \mathrm{ng} / \mathrm{mL}$ and $500 \mathrm{ng} / \mathrm{mL}$ in a single batch. Acceptance was determined by ECL values of high- and low-spiked samples being within $80-120 \%$ of those for buffer spiked with equivalent antibody.

Matrix effects were assessed using hemolyzed pooled serum samples $(1000 \mathrm{mg} / \mathrm{dL})$ spiked with $\mathrm{pAb}$ at 20,000 and $40.8 \mathrm{ng} / \mathrm{mL}$ and lipemic pooled serum samples spiked with pAb at 20,000 and $80.0 \mathrm{ng} / \mathrm{mL}$. Acceptance was determined by the samples scoring negative for unspiked and positive for spiked samples.

Sensitivity was assessed using mouse mAb spiked into NHS at concentrations ranging from 20.0 to $0.00985 \mathrm{ng} /$ $\mathrm{mL}$ (before application of MRD of 4), prepared 6 independent times, and analyzed in 6 runs by 2 different analysts. Sensitivity was also evaluated using pAb under the same conditions. Sensitivity was determined by the lowest concentration $(\mathrm{ng} / \mathrm{mL})$ of antibody determined positive above the screening assay cut point.

Drug tolerance studies were conducted in the screening assay to assess the sensitivity of the assay in the presence of dostarlimab. The assessment was conducted independently using both $\mathrm{mAb}$ and $\mathrm{pAb}$. Acceptance was determined by the highest drug concentration at which the PC remained positive.

The stability of the assays was assessed at different time points and temperatures, including $23 \mathrm{~h} 55 \mathrm{~min}$ at room temperature, $24 \mathrm{~h}$ at $2-8{ }^{\circ} \mathrm{C}$, and 5 freeze-thaw cycles from $-80{ }^{\circ} \mathrm{C}$. Acceptance criteria were PC samples that remained positive and had a percent coefficient of variation $(\% \mathrm{CV}) \leq 20 \%$ for replicates.

Robustness of the assays, both screening and confirmatory, was evaluated for the incubation time at each step of the assay, including block, MM, sample (screening), drug (confirmatory), and streptavidin plate (confirmatory).

The acceptance criteria for in-study runs were established using all validation $\mathrm{PC}$ ( $\mathrm{NC}$ and $\mathrm{PCs}$ ) results, except the data from the assay robustness evaluation. 
The validated method has been applied to the GARNET trial (NCT02715284) for both FDA and EMA approvals and associated labels of dostarlimab (ClinicalTrials.gov 2016; European Medicines Agency 2021; Jemperli 2021).

\section{Results}

\section{Cut points}

\section{Source of variation}

NC ECL values. None of the NC values had a high \%CV (> 20\%); thus, all values were used in the NC analysis. No values were identified as statistical outliers, leaving all $72 \mathrm{NC}$ values in the final analyses. Model assumptions were confirmed by the Shapiro-Wilk test for normality of conditional residual values $(P=0.086)$ but were not confirmed by the Levene's test for homogeneity of within-run sample variances $(P<0.001)$. A statistically significant difference was observed among the run means $(P<0.001)$.

\section{$S / N$ ratio values}

None of the ECL values had a high \%CV (> 20\%); thus, all 306 values were included in this analysis. The linear mixed effects ANOVA of the log-transformed $\mathrm{S} / \mathrm{N}$ ratio values identified 68 values as outliers. Twenty-seven values were identified as analytical, or method-level, outliers and 8 samples (41 additional values) were identified as biological, or patient-level, statistical outliers, leaving a total of 238 values for cut point assessment. No statistically significant differences were observed among the least square means for the fixed model effects $(P>0.05)$.

Differences among individual samples contributed 91.2\% of the total random variation in log-transformed $\mathrm{S} / \mathrm{N}$ ratio values. The remaining variation was due to analytical components: $2.9 \%$ due to run and $5.9 \%$ due to other residual effects. Model normality assumptions were confirmed by the Shapiro-Wilk test for the conditional residual values $(P=0.60)$ and for the sample BLUP values $(P=0.12)$. Levene's test confirmed the homogeneity assumption for intra-plate serum sample variances among plates $(P=0.24)$, and no statistically significant differences were observed among the run-plate mean values $(P=0.092)$. The normality assumption was not confirmed by the Shapiro-Wilk test for the distribution of the actual $\log \mathrm{S} / \mathrm{N}$ values used in the analysis $(P<0.001)$; however, the skewness coefficient $(0.856)$ was within the acceptance limits to allow the use of the parametric cut point estimates.

\section{Percent inhibition}

None of the $306 \%$ INH values was identified as having a \%CV (> 20\%). The linear mixed effects ANOVA of the 306 (untransformed) \%INH values identified 50 values as outliers. Fifteen values were identified as analytical outliers, and 6 samples (35 additional values) were identified as biological statistical outliers. These outliers were excluded from the cut point assessment, leaving a total of 256 values.

No statistically significant differences were observed among the least square means for the fixed model effects $(P>0.05)$. Normality assumptions were confirmed by the Shapiro-Wilk test for the conditional residuals $(P=0.74)$ but were not confirmed for the BLUP values $(P=0.011)$. The normality assumption was not confirmed by the Shapiro-Wilk test for the distribution of the actual \%INH values $(P<0.001)$; however, the skewness coefficient $(0.777)$ was within the acceptance limits to allow the use of the parametric cut point estimates.

\section{Cut point factor determination}

The parametric floating screening cut point factor of 1.02 was determined for application in the tier 1 screening assays; the nonparametric estimate of 1.11 is also valid and may be used. The confirmatory assay cut point was $36.5 \%$ for parametric and $40.7 \%$ for nonparametric, and the estimated titer cut point factor was 1.19. Although both the parametric and nonparametric screening cut point estimates are valid, use of the parametric estimate of 1.02 in the validation samples identified approximately $11 \%$ of the values as potentially positive, whereas the nonparametric estimate of 1.11 performed more closely to the prescribed $5 \%$ level (Table 3). Therefore, the 1.11 cut point factor was chosen. The same was observed for the confirmatory cut

Table 3 Frequency of values above and below cut point estimates following outlier removal

\begin{tabular}{|c|c|c|c|c|c|c|}
\hline Type & Error rate & Cut point & Above & $\%$ Above & Below & $\%$ Below \\
\hline \multicolumn{7}{|c|}{ Frequency of $\mathrm{S} / \mathrm{N}$ ratio values above and below the screening cut point estimates following outlier removal } \\
\hline Parametric & $5 \%$ & 1.02 & 27 & 11.34 & 211 & 88.66 \\
\hline Nonparametric & $5 \%$ & 1.11 & 11 & 4.62 & 227 & 95.38 \\
\hline \multicolumn{7}{|c|}{ Frequency of percent inhibition values above and below the confirmatory cut point estimates following outlier removal } \\
\hline Parametric & $1 \%$ & 36.54 & 10 & 3.91 & 246 & 96.09 \\
\hline Nonparametric & $1 \%$ & 40.73 & 2 & 0.78 & 254 & 99.22 \\
\hline
\end{tabular}


point. When the nonparametric cut point of $40.7 \%$ was used, the identified positive rate was about $0.78 \%$, which is closer to the defined $1 \%$ false-positive rate (Table 3).

Figure 1 provides a bivariate scatter plot of the platespecific log-transformed ECL values from the human serum samples versus the log-transformed ECL values of the NC on the corresponding plates. The linear relationship between mean values with a slope of 1.19 supports the application of a floating cut point factor for screening test samples for the presence of antibodies to dostarlimab, while a slope of 0 indicates that a fixed cut point will perform as well as a floating cut point.

Figure 2 presents a scatter plot of the \% INH mean values versus the associated $\mathrm{S} / \mathrm{N}$ ratio mean values for each individual sample. The $\mathrm{S} / \mathrm{N}$ ratio nonparametric cut point and the \%INH 99\% nonparametric cut point are also shown in Fig. 2. The majority of the sample data were well within the limits of the screening and confirmatory cut points, and as the $\mathrm{S} / \mathrm{N}$ ratio increased so did the \%INH value.

\section{False-negative rate}

None of the LPC $(40.0 \mathrm{ng} / \mathrm{mL}) \mathrm{S} / \mathrm{N}$ ratio values were identified as "analytic" outliers, leaving all $18 \mathrm{~S} / \mathrm{N}$ ratio values to be used in the estimation of the error rate. The false-negative error rate of $<0.1 \%$ was computed using both parametric and nonparametric cut points of 1.02 and 1.11, respectively. If the desired false-negative rate is $1 \%$, the desired mean $\mathrm{S} / \mathrm{N}$ ratio value of 1.11 or 1.21 is $62 \%$ or $58 \%$ lower than the mean ratio of 2.90 with the current LPC sample. Thus, a second LPC at a concentration of $3.45 \mathrm{ng} / \mathrm{mL}$ was added to ensure a $1 \%$ false-negative rate for day-to-day sample analysis.

\section{Method validation results}

Table 4 provides a summary of the overall validation results.

\section{Precision of positive controls}

Intra-assay and inter-assay precision for the screening assay (ECL no drug) was below $10 \%$ for all $3 \mathrm{pAb}$ PCs, LPC (40.0 ng/mL), MPC, and HPC. The added pAb LPC (3.45 $\mathrm{ng} / \mathrm{mL})$ for the screening assay, which

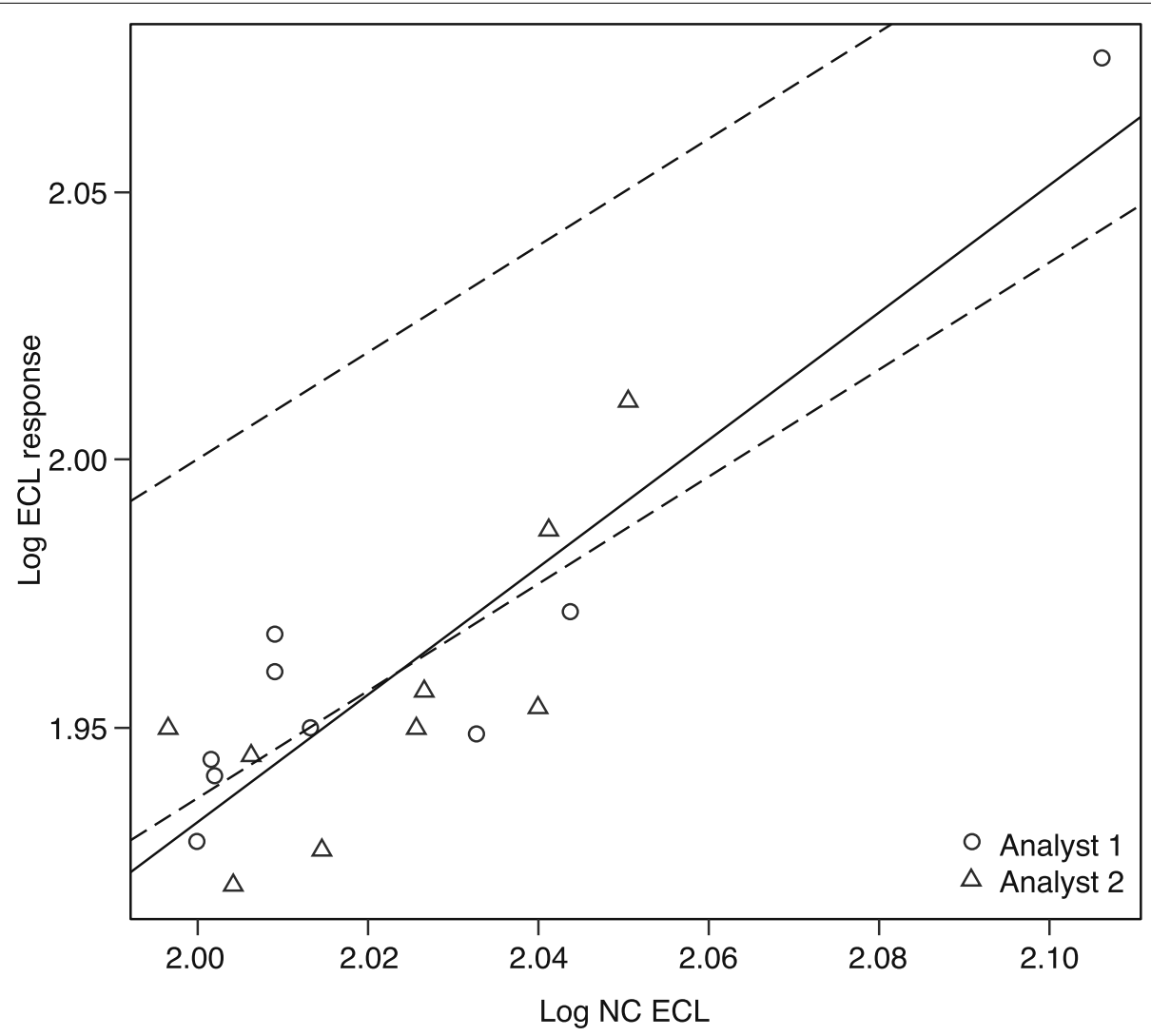

Fig. 1 Plot of log (ECL response) of human serum samples versus log (ECL response) of corresponding negative controls. The solid line is a regression line with slope $=1.18804$ and intercept $=-0.44367$. The short-dashed line is a regression line with slope restricted to 1 and intercept $=$ -0.06317 . The long-dashed line is a regression line with the slope restricted to 1 and intercept restricted to 0 


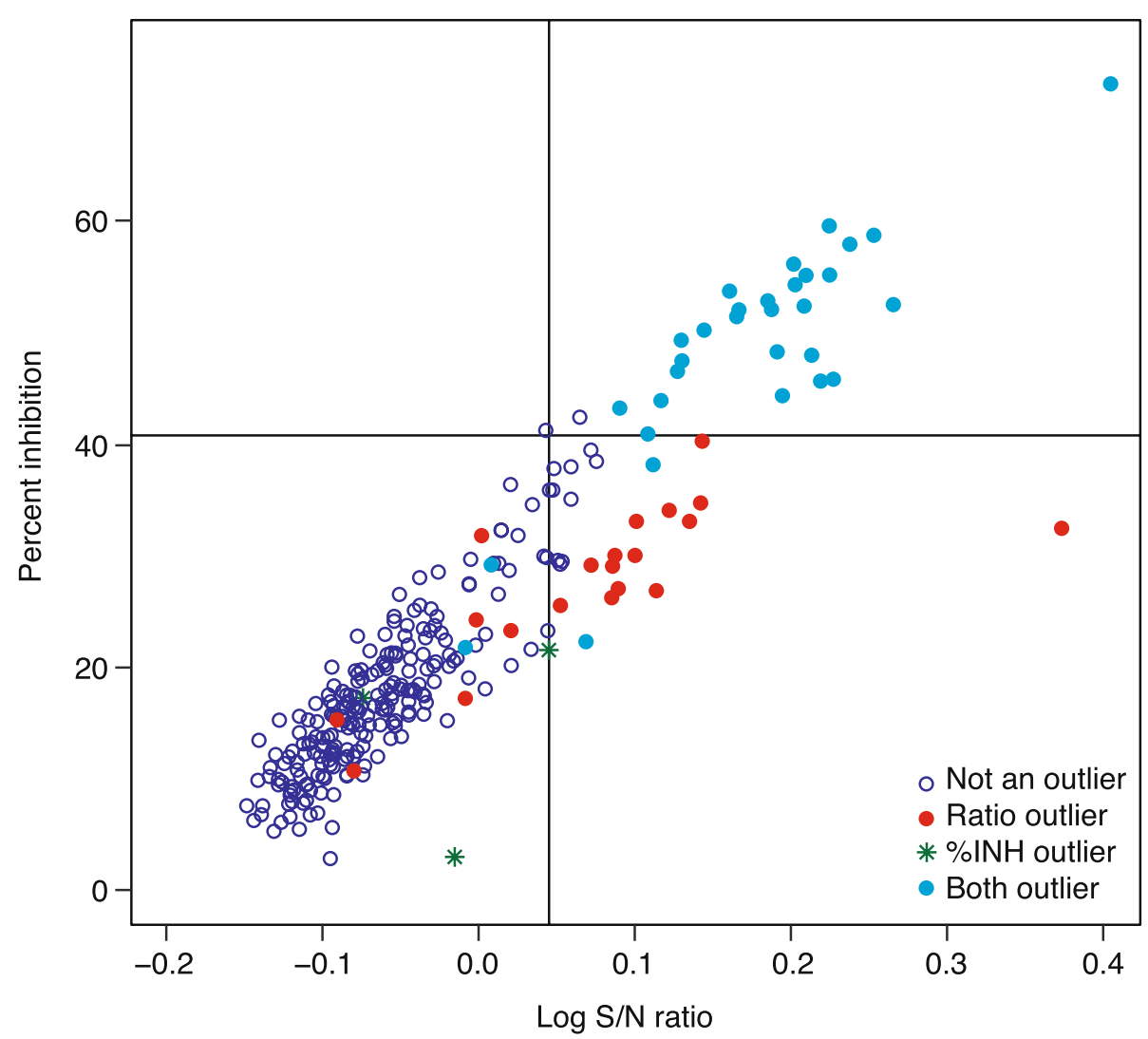

Fig. 2 Plot of percent inhibition versus log $\mathrm{S} / \mathrm{N}$ ratio values for all serum samples in study. The vertical reference line is the $95 \%$ parametric screening cut point of 0.045, which corresponds to an $\mathrm{S} / \mathrm{N}$ ratio value of 1.109. The horizontal reference line is the $99 \%$ parametric confirmation cut point of 40.7. PINH is calculated as (signal sample without drug — signal sample with $405 \mu \mathrm{g} / \mathrm{mL}$ drug)/signal sample without drug $\times 100 \%$

was used to fulfill the $1 \%$ false-negative rate for sample analysis, had inter-assay precision at $10.5 \%$. Intra-assay and inter-assay precision for the confirmatory assay (ECL with drug) was below $5 \%$ and $10 \%$, respectively, for all $3 \mathrm{pAb}$ PCs, LPC (40.0 ng/mL), MPC, and HPC.

\section{Precision of negative controls}

Intra-assay precision was extrapolated from the sample analysis runs in which 5 replicates of $\mathrm{NC}$ were run in duplicate ( $n=10$ wells) on each screening assay plate. The $\% \mathrm{CV}$ ranged from 1.3 to $17.2 \%$ over the 76 passing runs. A similar analysis was performed for the 16 rejected runs. One of the 16 runs had a $\% \mathrm{CV}$ of $197 \%$. The remaining 15 runs had \%CV ranging from 1.3 to $17.7 \%$. These data support acceptable intra-assay precision for the $\mathrm{NC}$ in the screening assay. Inter-assay precision for the screening assay (ECL no drug) was $7.0 \%$ for the NC. Inter-assay precision for the confirmatory assay (ECL with drug) was $7.6 \%$ for the NC.

\section{Precision of endpoint titers}

Endpoint titers were determined for the pAb HPC, MPC, and LPC (40 ng/mL) samples in a total of 4 runs by 2 analysts (2 runs each). Each sample was serially diluted 1:3 on 4 independent occasions, and the plate-specific titer cut point was determined and reported as the reciprocal of the last dilution with an ECL value above the titer cut point. For the pAb LPC ( $40 \mathrm{ng} / \mathrm{mL})$ and MPC, all 4 runs resulted in endpoint titers within a single threefold dilution and, therefore, met the acceptance criteria. In one batch, the HPC represented an outlier, with a 2 dilutionstep difference in endpoint titer as compared with the other 3 batches. The precision is adequate for a titration assay. Based on these data, in the assessment of treatment-boosted ADAs, a single dilution-step difference in titer is within the expected measurement error of the analytical method. Therefore, at least a ninefold increase in titer value was required for a treatment-boosted response for the change to be meaningful (US Food and Drug Administration 2019). 
Table 4 Validated assay summary

\begin{tabular}{|c|c|}
\hline Analytical performance characteristic & Results \\
\hline \multicolumn{2}{|l|}{ Screening assay validation } \\
\hline Screening cut point & $\begin{array}{l}\text { Cut point factor }=1.11 \text {, based on a nonparametric estimate, and representing a } \\
4.6 \% \text { false-positive error rate }\end{array}$ \\
\hline Precision $(\% \mathrm{CV})$ intra-batch by operator & $\begin{array}{l}3.6 \text { to } 4.7 \% \mathrm{LPC}(40.0 \mathrm{ng} / \mathrm{mL}) \\
2.5 \text { to } 4.5 \% \mathrm{MPC} \\
4.1 \text { to } 7.6 \% \mathrm{HPC} \\
1.3 \text { to } 17.2 \% \mathrm{NC}\end{array}$ \\
\hline Precision (\%CV) inter-batch overall ( $n=12$ assay by 2 operators) & $\begin{array}{l}10.5 \% \text { LPC }(3.45 \mathrm{ng} / \mathrm{mL})^{\mathrm{a}} \\
8.3 \% \mathrm{LPC}(40.0 \mathrm{ng} / \mathrm{mL}) \\
8.5 \% \mathrm{MPC} \\
7.2 \% \mathrm{HPC}\end{array}$ \\
\hline Hook effect (313 ng/mL to 40,000 ng/mL) & $\begin{array}{l}\text { ECL values increase with increasing concentration and/or plateau at the highest } \\
\text { level. No hook effect detected }\end{array}$ \\
\hline $\begin{array}{l}\text { Selectivity of spiked monoclonal antibody } \\
10 \text { Matrix lots of normal human serum } \\
10 \text { Matrix lots of cancer human serum }\end{array}$ & $\begin{array}{l}80 \% \text { of spikes prepared in normal samples recovered within } 80-120 \% \\
70 \% \text { of spikes prepared in cancer samples recovered within } 80-120 \%\end{array}$ \\
\hline Hemolyzed serum (approximately 1000 mg/dL) & $\begin{array}{l}\text { HPC and LPC ( } 40 \mathrm{ng} / \mathrm{mL}) \text { spiked into hemolyzed serum samples correctly } \\
\text { score positive. Unspiked score negative }\end{array}$ \\
\hline Lipemic serum (visually lipemic) & Spike samples score positive. Unspiked score negative \\
\hline Sensitivity & $\begin{array}{l}\text { The calculated sensitivity using mouse monoclonal antibody is } 0.328 \mathrm{ng} / \mathrm{mL} \text { and } \\
\text { with the rabbit polyclonal antibody, } 2.83 \mathrm{ng} / \mathrm{mL} \text {. Both were determined without } \\
\text { spiking-in drugs }\end{array}$ \\
\hline Drug tolerance & $\begin{array}{l}\text { The screening assay is tolerant to } 250 \mu \mathrm{g} / \mathrm{mL} \text { of drug when } 500 \mathrm{ng} / \mathrm{mL} \text { of antibody } \\
\text { is present }\end{array}$ \\
\hline Room temperature stability in serum: 23 h 55 min & $\% C V \leq 20 \%$ for the replicates of PC samples and remain positive \\
\hline Refrigerated stability in serum: $24 \mathrm{~h}$ & $\% C V \leq 20 \%$ for the replicates of PC samples and remain positive \\
\hline Freeze/thaw stability in serum: 1 to 5 cycles $\left(-80^{\circ} \mathrm{C} / \mathrm{RT}\right)$ & $\% C V \leq 20 \%$ for the replicates of PC samples and remain positive \\
\hline $\begin{array}{l}\text { Robustness of screening assay } \\
\text { Block ( } 25 \text { to } 35 \mathrm{~min}) \\
\text { Master mix (170 to } 190 \mathrm{~min}) \\
\text { Sample ( } 50 \text { to } 70 \mathrm{~min})\end{array}$ & $\begin{array}{l}\% \text { Difference for the robustness timing is } \leq 20 \% \text { compared with the recom- } \\
\text { mended incubation times }\end{array}$ \\
\hline \multicolumn{2}{|l|}{ Confirmatory assay validation } \\
\hline Confirmatory cut point & $\begin{array}{l}\text { Cut point }=40.7 \% \text { inhibition, based on a nonparametric estimate, representing a } \\
1.0 \% \text { false-positive rate }\end{array}$ \\
\hline Precision (\%CV) of ECL values with drug intra-batch & $\begin{array}{l}\text { HPC: } 3.1 \% \\
\text { MPC: } 2.4 \% \\
\text { LPC: } 4.3 \%(40 \mathrm{ng} / \mathrm{mL})\end{array}$ \\
\hline Precision (\%CV) of ECL values with drug inter-batch & $\begin{array}{l}\text { HPC: } 9.8 \% \\
\text { MPC: } 9.1 \% \\
\text { LPC: } 8.9 \%(40 \mathrm{ng} / \mathrm{mL})\end{array}$ \\
\hline $\begin{array}{l}\text { Robustness of confirmatory assay } \\
\text { Block (25 to } 35 \mathrm{~min} \text { ) } \\
\text { Master mix (170 to } 190 \mathrm{~min} \text { ) } \\
\text { Drug (57 to } 65 \mathrm{~min}) \\
\text { Streptavidin plate (55 to } 65 \mathrm{~min})\end{array}$ & $\%$ Difference for the robustness timing is $\leq 20 \%$ compared with \\
\hline \multicolumn{2}{|l|}{ Titer assay validation } \\
\hline Titer cut point & $\begin{array}{l}\text { Calculated to represent a } 0.1 \% \text { false-positive rate, used to determine the end point } \\
\text { titer of a sample titered in the method }\end{array}$ \\
\hline Precision of titer determination & $\begin{array}{l}\text { Endpoint titers between analysts are within one dilution step for } 3 \text { of } 4 \text { samples } \\
\text { and within } 2 \text { dilutions steps for the remaining sample. }\end{array}$ \\
\hline
\end{tabular}

${ }^{a}$ This additional low control was added after this validation study was complete

\section{Sensitivity}

The sensitivity of the screening assay was determined using both mouse mAb and rabbit pAb spiked into NHS at concentrations ranging from 20.0 to $0.00985 \mathrm{ng} / \mathrm{mL}$ (before application of the MRD of 4), prepared 6 independent times and analyzed in 6 runs by 2 different analysts. The sensitivity was determined as the upper limit of the 95th CI of the mean of the intercept concentrations 
at the cut points from 12 runs. The data indicate the method sensitivity is $0.328 \mathrm{ng} / \mathrm{mL}$ for $\mathrm{mAb}$ and $2.83 \mathrm{ng} /$ $\mathrm{mL}$ for $\mathrm{pAb}$ without spiking-in drugs. The 99th $\mathrm{CI}$ was used to estimate the appropriate level for a low-control pAb that would represent a $1 \%$ failure rate at $3.45 \mathrm{ng} / \mathrm{mL}$.

\section{Selectivity}

Ten serum samples from healthy individuals and 10 serum samples from individuals with cancer were evaluated for recovery of spiked pAb at $40.0 \mathrm{ng} / \mathrm{mL}$ and 20,000 $\mathrm{ng} / \mathrm{mL}$. The batch passed all acceptance criteria. Selectivity did not pass, owing to a significant reduction in signal in spiked samples as compared with buffer. This finding is attributable to the fact that the rabbit pAb is dostarlimabaffinity purified and, therefore, retains anti-human Ig reactivity. The assigned concentration was that of total Ig, inclusive of anti-human Ig species. When human serum was spiked with pAb, the loss of signal was due to binding of anti-human Ig antibodies to human Ig in the sample. Ten serum samples from normal individuals and patients with cancer were evaluated for recovery of spiked mAb at $40.0 \mathrm{ng} / \mathrm{mL}$ and $500 \mathrm{ng} / \mathrm{mL}$. A respective 8/10 (80\%) and $7 / 10(70 \%)$ samples passed the acceptance criteria of $\leq$ $20 \%$ difference from an equivalent spike into assay buffer.

\section{Drug tolerance}

This assessment was conducted using both mAb and $\mathrm{pAb}$ independently. The drug tolerance for each antibody/ level was reported as the highest concentration of the drug for which the $\mathrm{PC}$ readout at a defined concentration was above the cut point. Using the $\mathrm{mAb}$, the screening assay was demonstrated to be tolerant up to $250 \mu \mathrm{g} / \mathrm{mL}$ of dostarlimab when $500 \mathrm{ng} / \mathrm{mL}$ of $\mathrm{mAb}$ was present, or $125 \mu \mathrm{g} / \mathrm{mL}$ of dostarlimab when $100 \mathrm{ng} / \mathrm{mL}$ of $\mathrm{mAb}$ was present. Lower tolerance at $62.5 \mu \mathrm{g} / \mathrm{mL}$ in the presence of $500 \mathrm{ng} / \mathrm{mL}$ was observed when the rabbit $\mathrm{pAb}$ was used; however, given that the pAb was not fully purified, a conclusion cannot be drawn with confidence.

\section{Matrix effects}

Hemolyzed pooled serum samples were spiked with pAb at 20,000 and $40.8 \mathrm{ng} / \mathrm{mL}$. Lipemic pooled serum samples were spiked with pAb at 20,000 and $80.0 \mathrm{ng} / \mathrm{mL}$. The initial results demonstrated no interference from lipemic serum. The hemolyzed spiked pool scored positive and the unspiked pool incorrectly scored positive as well. The hemolyzed sample containing $1100 \mathrm{mg} / \mathrm{dL}$ was serially diluted to produce proportionally decreasing levels of hemolysis and tested against the spiked and unspiked pools. Once again, the unspiked sample returned a positive result regardless of hemolysis level. To further understand whether this was a pooled sample with nonspecific reactivity or if the positivity was due to hemolysis, 5 individual samples with various degrees of hemolysis were evaluated. All 5 samples scored correctly, with spiked samples scoring positive and unspiked scoring negative, leading to the conclusion that something unique about the pool caused a positive result. The possibility exists that the pool contained pre-existing antibodies.

\section{Robustness}

Studies were conducted to assess the robustness of the timing of incubation steps for both screening and confirmatory assays, and the findings were used to define the outer boundaries of incubation timing in the laboratory method. The percent difference was calculated for the ECL values between the baseline timing for all steps and for the ECL values for steps with altered incubation times. A difference of $<20 \%$ was observed for all samples and was considered acceptable (Table 5).

\section{Acceptance criteria for in-study runs}

Before the initiation of the in-study phase, in-study plate acceptance criteria were defined using all the PC results generated during this validation study. The results are listed in Table 6. The limits listed below can be recalculated using additional data from the in-study phase when there is a significant change in the assay conditions or reagents and/or if the data used during pre-study validation were found to be inadequate:

- $99.5 \%$ upper limit of NC ECL value

- $99 \%$ upper and lower limit of pAb LPC (40 ng/mL) ECL value

- $99 \%$ upper and lower limit of pAb HPC ECL value

- >cut point ECL for pAb 3.45 ng/mL LPC

Upper limits are not considered to be critical for the PC because the consequence of a "higher than normal" assay signal can result in a higher incidence of reactive samples. This finding can subsequently prove to be nonspecific by the confirmatory assay and, therefore, does not affect the false-negative rate of detection. For the confirmatory assay, in addition to the ECL acceptance criteria, the pAb HPC, MPC, and LPC (40 ng/mL) should be inhibited by at least $40.7 \%$, the nonparametric confirmatory cut point selected for sample analysis.

\section{Evaluation of acid dissociation}

Table 7 summarizes the comparison of method sensitivity with spiking-in drugs with or without acid dissociation at different dissociation times for a concentration of $300 \mathrm{mM}$ AA with $100 \mu \mathrm{g} / \mathrm{mL}$ of free drug. The method sensitivity levels were comparable with or without acid dissociation when using $\mathrm{AA}$ at $300 \mathrm{mM}$ for the different 
ơ

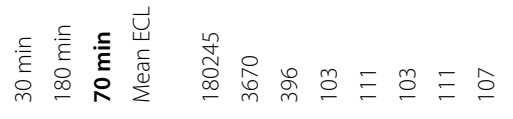

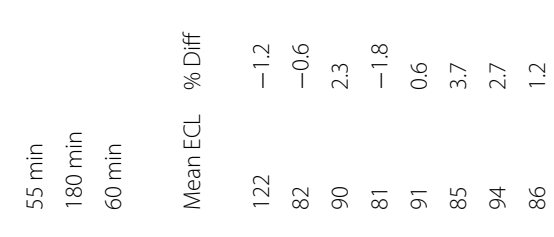

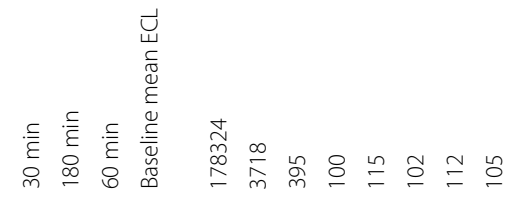

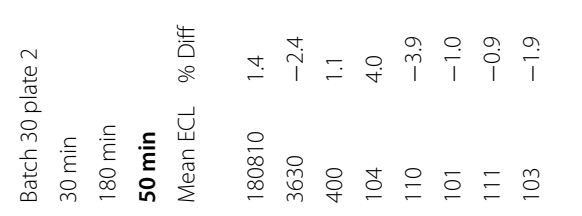

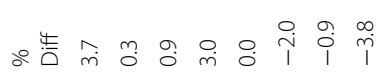

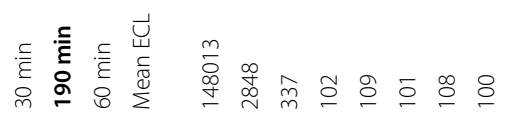

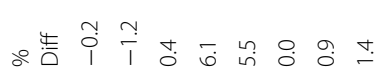

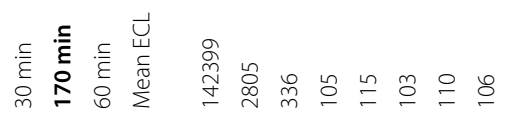

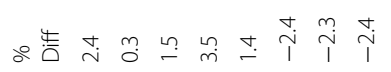

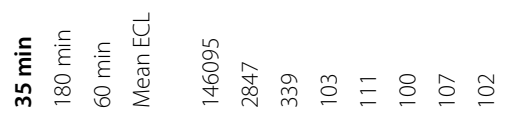

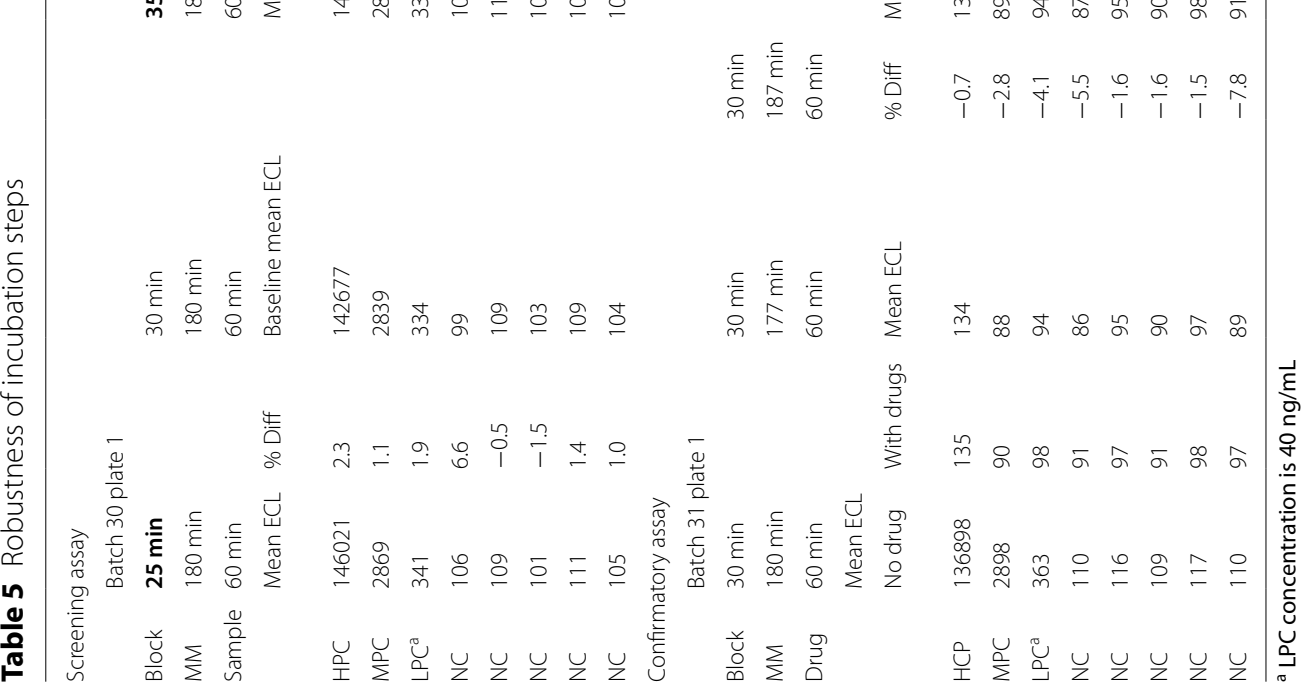

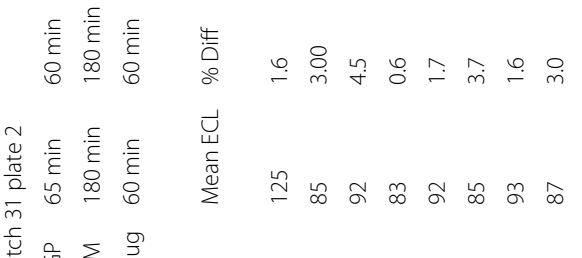

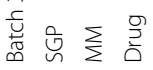

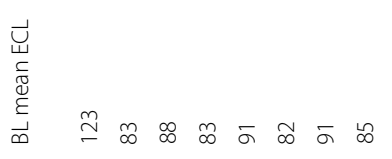

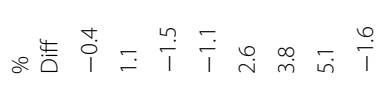

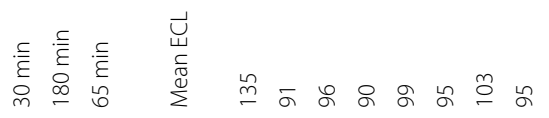

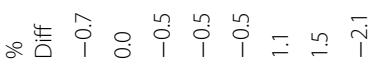

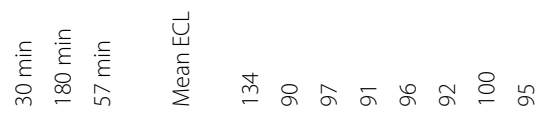

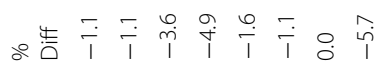
$\breve{\uplus}$ 党 
Table 6 Summary of control ECL range setting

\begin{tabular}{llllll}
\hline Mean ECL & SD & $($ t0.005 $\times$ SD) & $\begin{array}{l}\text { Mean }+ \\
\text { (t0.005 } \times \\
\text { SD) }\end{array}$ & $\begin{array}{l}\text { Mean }- \\
\text { (t0.005 } \times \\
\text { SD) }\end{array}$ \\
\hline NC & 111 & 10.8 & 32 & 143 & NA \\
LPC $^{\mathbf{a}}$ & 333 & 36.0 & 107 & 440 & 227 \\
MPC & 2802 & 315.4 & 937 & 3739 & 1865 \\
HPC & 145765 & 14846 & 44113 & 189878 & 101652 \\
\hline
\end{tabular}

${ }^{a} \mathrm{LPC}$ concentration is $40 \mathrm{ng} / \mathrm{mL}$. The $99.5 \%$ upper limit of NC was calculated as mean $+t(0.005, n-1) \times S D$, where $t(0.005$, df) corresponds to a $0.5 \%$ error rate and $n$ represents the number of independent replicate $\mathrm{NC}$ results used in this evaluation. The $99 \%$ range limits for pAb LPC $(40 \mathrm{ng} / \mathrm{mL}), \mathrm{MPC}$ and HPC ECL values were calculated as mean $\pm \mathrm{t}(0.005, n-1) \times \mathrm{SD}$, where $t(0.005$, df $)$ and $n$ are defined as above and correspond to a $1 \%$ failure rate

acid dissociation times examined (15, 30, and $45 \mathrm{~min})$. As highlighted in green, when considering higher than $75 \%$ recovery as guidance for biologics criteria, the method sensitivity at $156.25 \mathrm{ng} / \mathrm{mL}$ was determined to be the same across all the incubation times tested.

Table 8 summarizes the comparison of method sensitivity with spiking-in drugs with or without a 45 -min acid dissociation time at different AA concentrations. The free drug concentration was $100 \mu \mathrm{g} / \mathrm{mL}$. These data suggest that the method sensitivity was comparable with or without acid dissociation at $600 \mathrm{mM}$ with 45 -min AA dissociation. More outliers were observed for $900 \mathrm{mM}$ AA dissociation, where the conditions were apparently too acidic, which led to indeterminable sensitivity evaluation. The $300 \mathrm{mM}$ AA method demonstrated less sensitivity than when acid dissociation was not applied.

\section{Application of the method for clinical sample analysis}

There were 1543 samples tested for antibodies to dostarlimab for the second-line endometrial cancer biologics license application (BLA) filing of the GARNET study. Of

Table 7 Comparison of the method sensitivity without or at different acid dissociation time

\begin{tabular}{|c|c|c|c|c|c|c|c|c|c|c|c|c|}
\hline \multirow[t]{2}{*}{ PC conc. (ng/mL) } & \multicolumn{3}{|c|}{ No AA $100 \mu \mathrm{g} / \mathrm{mL}$ free drug } & \multicolumn{3}{|c|}{$\begin{array}{l}15 \mathrm{~min} \text { AA } 100 \mu \mathrm{g} / \mathrm{mL} \text { free } \\
\text { drug }\end{array}$} & \multicolumn{3}{|c|}{$\begin{array}{l}30 \mathrm{~min} \text { AA } 100 \mu \mathrm{g} / \mathrm{mL} \text { free } \\
\text { drug }\end{array}$} & \multicolumn{3}{|c|}{$\begin{array}{l}45 \mathrm{~min} \mathrm{mM} \text { AA } 100 \mu \mathrm{g} / \mathrm{mL} \\
\text { free drug }\end{array}$} \\
\hline & Signal & $\mathrm{S} / \mathrm{N}$ & $\begin{array}{l}\% \\
\text { Recovery } \\
\text { mean }\end{array}$ & Signal & $\mathrm{S} / \mathrm{N}$ & $\begin{array}{l}\% \\
\text { Recovery } \\
\text { mean }\end{array}$ & Signal & $\mathrm{S} / \mathrm{N}$ & $\begin{array}{l}\% \\
\text { Recovery } \\
\text { mean }\end{array}$ & Signal & $\mathrm{S} / \mathrm{N}$ & $\begin{array}{l}\% \\
\text { Recovery } \\
\text { mean }\end{array}$ \\
\hline 5000 & 1343 & 4.8 & 100.9 & 2579 & 9.2 & 103.0 & 2553 & 9.1 & 100.7 & 2855 & 10.2 & 103.4 \\
\hline 2500 & 734 & 2.6 & 98.0 & 1182 & 4.2 & 95.7 & 1243 & 4.4 & 97.3 & 1332 & 4.7 & 94.1 \\
\hline 1250 & 482 & 1.7 & 102.0 & 690 & 2.5 & 100.8 & 740 & 2.6 & 105.5 & 812 & 2.9 & 105.0 \\
\hline 625 & 350 & 1.2 & 96.0 & 440 & 1.6 & 95.2 & 448 & 1.6 & 95.9 & 479 & 1.7 & 95.8 \\
\hline 312.5 & 303 & 1.1 & 107.9 & 374 & 1.3 & 126.4 & 344 & 1.2 & 99.6 & 369 & 1.3 & 110.3 \\
\hline 156.25 & 271 & 1.0 & 90.4 & 295 & 1.0 & 75.3 & 291 & 1.0 & 94.2 & 280 & 1.0 & 78.1 \\
\hline 78.125 & 270 & 1.0 & 172.4 & 306 & 1.1 & 206.4 & 278 & 1.0 & 131.9 & 284 & 1.0 & 169.8 \\
\hline 0 & 246 & 0.9 & & 257 & 0.9 & & 250 & 0.9 & & 231 & 0.8 & \\
\hline
\end{tabular}

The bolded values indicate the row with the lowest PC conc which has a recovery $\geq 30 \%$, defined as the sensitivity for each condition

Table 8 Comparison of the method sensitivity without or at different acid dissociation concentration

\begin{tabular}{|c|c|c|c|c|c|c|c|c|c|c|c|c|}
\hline \multirow[b]{2}{*}{ PC conc. (ng/mL) } & \multicolumn{3}{|c|}{$\begin{array}{l}\text { No AA } 100 \mu \mathrm{g} / \mathrm{mL} \text { free } \\
\text { drug }\end{array}$} & \multicolumn{3}{|c|}{$\begin{array}{l}300 \mathrm{mM} \mathrm{AA} 100 \mu \mathrm{g} / \mathrm{mL} \\
\text { free drug }\end{array}$} & \multicolumn{3}{|c|}{$\begin{array}{l}600 \mathrm{mM} \text { AA } 100 \mu \mathrm{g} / \mathrm{mL} \\
\text { free drug }\end{array}$} & \multicolumn{3}{|c|}{$900 \mathrm{mM} \mathrm{AA} 100 \mu \mathrm{g} / \mathrm{mL}$ free drug } \\
\hline & Signal & $\mathrm{S} / \mathrm{N}$ & $\begin{array}{l}\% \\
\text { Recovery } \\
\text { mean }\end{array}$ & Signal & $\mathrm{S} / \mathrm{N}$ & $\begin{array}{l}\% \\
\text { Recovery } \\
\text { mean }\end{array}$ & Signal & $\mathrm{S} / \mathrm{N}$ & $\begin{array}{l}\% \\
\text { Recovery } \\
\text { mean }\end{array}$ & Signal & $\mathrm{S} / \mathrm{N}$ & $\%$ Recovery mean \\
\hline 5000 & 1060 & 10.9 & 102.6 & 1435 & 13.2 & 104.8 & 1634 & 6.4 & 103.6 & 2241 & 1.4 & 100.0 \\
\hline 2500 & 574 & 5.9 & 98.5 & 713 & 6.5 & 92.6 & 912 & 3.5 & 95.2 & 1208 & 0.8 & $\mathrm{NaN}$ \\
\hline 1250 & 347 & 3.6 & 99.7 & 402 & 3.7 & 106.8 & 621 & 2.4 & 101.8 & 1646 & 1.0 & 380.0 \\
\hline 625 & 217 & 2.2 & 91.1 & 211 & 1.9 & 105.7 & 434 & 1.7 & 91.9 & 1403 & 0.9 & $\mathrm{NaN}$ \\
\hline 312.5 & 174 & 1.8 & 112.2 & 141 & 1.3 & 104.9 & 374 & 1.5 & 113.4 & 1610 & 1.0 & 1508.9 \\
\hline 156.25 & 131 & 1.4 & 87.8 & 95 & 0.9 & $\mathrm{NaN}$ & 307 & 1.2 & 72.7 & 1392 & 0.9 & $\mathrm{NaN}$ \\
\hline 78.125 & 131 & 1.4 & 175.6 & 143 & 1.3 & 434.3 & 341 & 1.3 & 300.8 & 1682 & 1.1 & 6116.9 \\
\hline 0 & 97 & 1.0 & $\mathrm{NaN}$ & 109 & 1.0 & $\mathrm{NaN}$ & 257 & 1.0 & $\mathrm{NaN}$ & 1589 & 1.0 & $\mathrm{NaN}$ \\
\hline
\end{tabular}

The bolded values highlight indicates the row with the lowest PC conc which has a recovery $\geq 30 \%$, defined as the sensitivity for each condition 
these, 1376 (89.2\%) were negative, 130 (8.4\%) confirmed positive, and 37 (2.4\%) were inconclusive. These results are based on having measured dostarlimab concentrations above the drug tolerance level determined using $500 \mathrm{ng} / \mathrm{mL} \mathrm{mAb}$ sensitivity tolerant up to $250 \mu \mathrm{g} / \mathrm{mL}$ of drug.

The assay drug tolerance level was established using surrogate PC antibodies. Upon detailed examination of the ADA results from actual study samples, 19 samples from 9 patients who screened positive for ADAs with drug concentrations higher than the assay drug tolerance level of $125 \mu \mathrm{g} / \mathrm{mL}$ (determined using the $100 \mathrm{ng} / \mathrm{mL}$ $\mathrm{mAb}$ PC). Four out of these 19 samples had dostarlimab concentrations $\geq 200 \mu \mathrm{g} / \mathrm{mL}$ (about $97 \%$ of the samples had pre-dose concentrations $<200 \mu \mathrm{g} / \mathrm{mL}$ at the recommended therapeutic dose of $500 \mathrm{mg}$ dostarlimab every 3 weeks for 4 cycles, followed by $1000 \mathrm{mg}$ every 6 weeks), with the highest concentration of $287 \mu \mathrm{g} / \mathrm{mL}$. Four of the 9 aforementioned patients had confirmed ADA-positive samples with dostarlimab concentrations $\geq 125 \mu \mathrm{g} / \mathrm{mL}$, including one with the highest measured drug concentration of $171 \mu \mathrm{g} / \mathrm{mL}$. In examining the ADA data profiles for these 4 patients, drug concentrations $\geq 125 \mu \mathrm{g} /$ $\mathrm{mL}$ and $<171 \mu \mathrm{g} / \mathrm{mL}$ did not impact the confirmatory results of ADA evaluation and the ability to measure the associated titer levels. The ADA signals and the changes in titers were sufficiently captured with the current assay with changing drug concentrations at different time points. Collectively, these data suggest that the current human ADA assay has superior drug tolerance for human ADAs compared with the surrogate PC that was used to calculate the assay drug tolerance level, as evident from the analysis above.

Additional evaluation of the drug concentration versus titer relationship from the post-treatment samples showed no trend in the impact of drug concentration on titer determination (Fig. 3). Most of the post-dose confirmed positive samples $(49 / 52)$ had low titers $(\leq$ $36)$. Such titers are likely to be of limited or no clinical impact. Moreover, the drug concentration ranges at each of the ADA titer levels overlapped greatly, with no clear trend of a relationship between the drug concentration ranges and titers. The absence of such trends suggests that within the concentration range and titer levels examined, the assay at its current tolerance was able to detect the ADA signal adequately in these clinical samples.

\section{Discussion}

Assay design

The 3-tier design approach to determine anti-dostarlimab ADAs was based on a bridging assay that detects most antibodies that bind to dostarlimab. Incubation of biotinylated dostarlimab and SULFO-TAG-labeled dostarlimab with a serum sample containing anti-dostarlimab

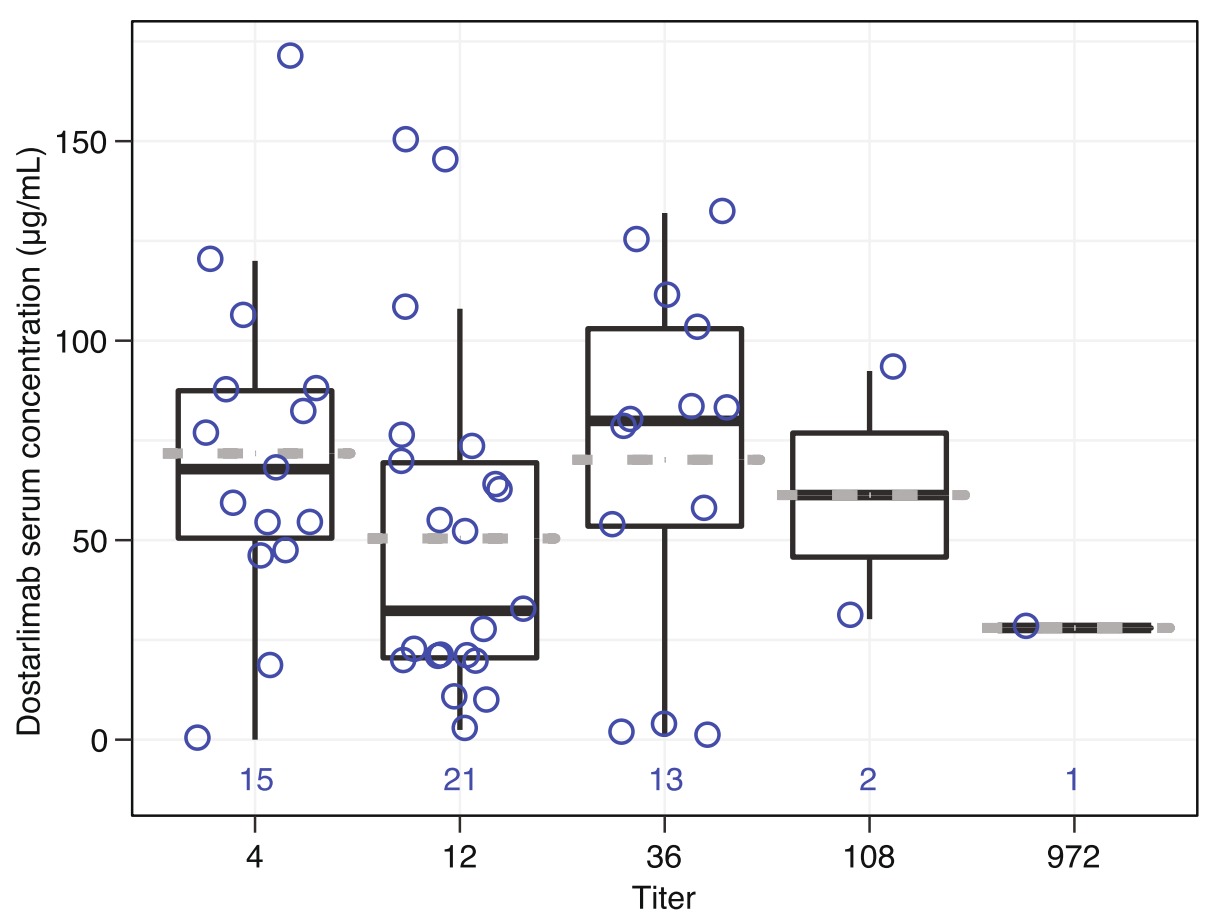

Fig. 3 Box plot of drug concentrations for each titer category. Median with box of $25 \%$ to $75 \%$; whiskers are minimum and maximum excluding outliers (1.5x of interquartile range); dashed gray line is the mean; numbers in blue show $\mathrm{N}$ per category 
antibodies allows the formation of a complex between the tagged dostarlimab molecules bridged by the ADAs from the serum sample. This complex, when added to a streptavidin MSD plate, binds to the wells through the streptavidin-biotin interaction. It also gives a positive proximity ECL signal based on the amount of SULFOTAG-labeled dostarlimab antibody that is captured in the complex. The 3-tiered approach was used for screening, confirmation, and characterization of ADA titer. This bridging assay should detect all ADA isotypes; however, some IgG4 may evade detection if heavy-chain exchange has occurred, through which the exchange of half antibody in vivo may create randomly bispecific antibodies (van der Neut Kolfschoten et al. 2007). However, naturally occurring serum IgG4 levels are below 4\%, and only a fraction of these are heterodimeric. Isotyping of ADA was not required because of the low immunogenicity incidence rate with low titer, no observed severe safety concern(s) associated with certain isotype(s) (such as types 1 and 2 hypersensitivity from $\operatorname{IgE}$ and $\operatorname{IgG/IgM,}$ respectively), and a lack of impact of ADAs on the PK, safety, and efficacy of dostarlimab (data on file) and other anti-PD-1 drugs (Bavencio 2017; Imfinzi 2017; Keytruda 2020; Libtayo 2018; Opdivo 2020; Tecentriq 2016).

\section{Controls}

Two PCs were used to support the method development and validation. A rabbit pAb was generated by immunizing rabbits and then using dostarlimab for affinity purification, without the removal of anti-human Ig. To correctly evaluate sensitivity, selectivity, and drug tolerance, a second PC of mouse mAb was included into the validation. Selectivity passed the criteria using the mouse mAb PC, and acceptable sensitivity of the method was obtained for both PCs without drug. In terms of drug tolerance, a difference was also seen between the 2 PCs. The rabbit pAb appeared to have less tolerance to the presence of dostarlimab (at $62.5 \mu \mathrm{g} / \mathrm{mL}$ in the presence of 500 $\mathrm{ng} / \mathrm{mL}$ of rabbit $\mathrm{pAb})$. Based on the selectivity data from the $\mathrm{pAb}$, more than $80 \%$ reduction in signal was observed (comparing to buffer). The rabbit pAb PC contained a fairly large quantity of anti-human Ig, which prevented us from correctly evaluating the drug tolerance of the assay. The drug tolerance established using the mouse mAb was $250 \mu \mathrm{g} / \mathrm{mL}$ in the presence of $500 \mathrm{ng} / \mathrm{mL}$ mouse $\mathrm{mAb}$ or $125 \mu \mathrm{g} / \mathrm{mL}$ in the presence of $100 \mathrm{ng} / \mathrm{mL}$ mouse $\mathrm{mAb}$. When counting an $80 \%$ signal reduction in the selectivity evaluation for $\mathrm{pAb}$, both the pAb and mAb had similar drug tolerance levels at about $250 \mu \mathrm{g} / \mathrm{mL}$ (assuming linear for the range of signals, $1-5$ folds of $62.5 \mu \mathrm{g} / \mathrm{mL}$, from $\mathrm{pAb})$. Based on the above analysis, the drug tolerance level determined using the mAb was used as the drug tolerance limit of the assay for reporting clinical sample results. Samples that scored negative in the assay but had measured drug levels above this drug tolerance limit were reported as "inconclusive" rather than negative. In the clinical study sample analysis, sets of pAb were used as PCs to mimic the real samples and functioned as a gate for the pass or fail of each run.

NCs are critical, especially when an analysis is based on a floating cut point factor. Two important aspects must be taken into consideration. When multiple lots of NHS are screened, lots with relatively low ECL readouts are preferred. A cut point factor $<1$ can be avoided with pooled lots of NHS with low ECL readouts, a scenario in which the cut point of the plate will be lower than the $\mathrm{NC}$ readout. In addition, because the cut point for each plate is based on the NC readouts, it is necessary to have enough pooled sera, from specified lots, available to complete an entire study without the need to perform partial validations to recalculate the cut points.

\section{Assay performance and regulatory expectations}

In 2019, the FDA updated requirements for ADA assay sensitivity from $250-500 \mathrm{ng} / \mathrm{mL}$ to $100 \mathrm{ng} / \mathrm{mL}$ based on the observation that some ADAs had clinical impact at concentrations as low as $100 \mathrm{ng} / \mathrm{mL}$ (US Food and Drug Administration 2019). The European Medicines Agency (EMA) does not provide guidance on a specific requirement for assay sensitivity (European Medicines Agency 2017; Kurki 2019). Many discussions between industry and government agencies on this topic and their alignments (results or agreements) are published as white papers every year. In 2017, the FDA and EMA recommendations were published, providing guidance that screening and confirmatory IgG and IgM ADA assays should achieve a sensitivity of at least $100 \mathrm{ng} / \mathrm{mL}$, although a limit of sensitivity greater than $100 \mathrm{ng} / \mathrm{mL}$ was acceptable depending on risk and prior knowledge (Gupta et al. 2017). The assay development described in this paper was initiated in 2015. With the consideration of future industry evolution and the potential for more stringent requirements, sensitivity at $500 \mathrm{ng} / \mathrm{mL}$ with drug tolerance of $250 \mu \mathrm{g} / \mathrm{mL}$ and $100 \mathrm{ng} / \mathrm{mL}$ with drug tolerance of $125 \mu \mathrm{g} / \mathrm{mL}$ were both established and validated. When implementing the $500 \mathrm{ng} / \mathrm{mL}$ sensitivity, about $98 \%$ of all pre-dose patient samples at the recommended therapeutic dose of different treatment cycles (data on file) should have drug concentrations below the drug tolerance level of $250 \mu \mathrm{g} / \mathrm{mL}$ at the time of ADA sample collection. The FDA endorsed the use of a sensitivity of $500 \mathrm{ng} / \mathrm{mL}$ based on the low risk of this molecular class and the additional supporting low risk of dostarlimab ADA impact to PK, efficacy, or safety (data on file). The EMA recommended a further adjustment in the drug tolerance level to $200 \mu \mathrm{g} / \mathrm{mL}$ 
from pre-dose samples at the recommended therapeutic dose, at the sensitivity of $100 \mathrm{ng} / \mathrm{mL}$. During the method development, we evaluated different ways to improve drug tolerance, including acid dissociation through AA. It is worth noting that the method without acid dissociation repeatedly and consistently detected ADAs with the same sensitivity as the presence of $100 \mu \mathrm{g} / \mathrm{mL}$ dostarlimab (Tables 7 and 8). Overall, the added step of acid dissociation did not improve the assay sensitivity in the presence of $100 \mu \mathrm{g} / \mathrm{mL}$ dostarlimab. Additionally, an increase in between-day variability in experimental practice and sample analysis was also evident in the noted outliers with some acid dissociation experiments. Without a guided standard curve, like the scenario in the ADA sample analysis, these outlier samples will not be correctly evaluated or categorized. Thus, acid dissociation was not implemented into the assay method. However, the investigation of acid dissociation during method development was not exhaustive. Different acids of different strengths and incubation times might be further investigated and alternate methods may be explored as well (Zoghbi et al. 2015). If the results from new evaluations (acid dissociation or alternate) demonstrate a much-improved drug tolerance and sensitivity with comparable assay performance, the established new method could be applied for future assessment of ADA response to dostarlimab treatment.

During the method development process, pAb LPC at $40 \mathrm{ng} / \mathrm{mL}$ was used for full method validation. After determination of the method sensitivity, the 99th CI was used to estimate the appropriate level for pAb $\mathrm{LPC}$ at $3.45 \mathrm{ng} / \mathrm{mL}$ that would represent a $1 \%$ failure rate. This lower LPC was included into all the sample analyses to gate the screening assay for false negatives. The inter-assay precision of $10.5 \%$ indicates the consistent performance of the assay as demonstrated in the full method validation. The low failure rate of the assay aligns with the projected rate of $1 \%$. This ADA method development is considered as an evolved process with the supporting information from method development, validation, and clinical applications ( $\mathrm{Lu}$ et al. 2021).

\section{Conclusion}

A 3-tiered ECL assay was designed and fully validated for the screening, confirmation, and titer determination of ADAs against dostarlimab. High drug tolerance at the sensitivity of both $500 \mathrm{ng} / \mathrm{mL}$ antibody $(250 \mu \mathrm{g} / \mathrm{mL}$ drug tolerance) and $100 \mathrm{ng} / \mathrm{mL}$ antibody $(125 \mu \mathrm{g} / \mathrm{mL}$ drug tolerance) allows the assay to support dostarlimab immunogenicity evaluation in the first clinical studies of dostarlimab for multiple indications (endometrial cancer and dMMR pan tumors), and to establish the initial immunogenicity profile for the United States Prescribing Information and EMA Summary of Product Characteristics (European Medicines Agency 2021; Jemperli 2021).

\begin{abstract}
Abbreviations
$\% C V$ : Percent coefficient of variation; \%INH: Percent inhibition; AA: Acetic acid; ADA: Anti-drug antibody; BLA: Biologics license application; conc.: Concentration; Diff.: Difference; dMMR: Mismatch repair deficient; ECL: Electrochemiluminescence; ECLIA: Electrochemiluminescence immunoassay; EMA: European Medicines Agency; FDA: Food and Drug Administration; HPC: High-positive control; Ig: Immunoglobulin; LC: Low cross; LPC: Low-positive control; mAb: Monoclonal antibody; MM: Mastermix incubation step; MPC: Mid-positive control; MRD: Minimum required dilution; NaN: No value can be determined; NC: Negative control; NHS: Normal human serum; pAb: PC antibody; PC: Positive control; PD-1: Programmed death 1; PD-L1: Programmed death ligand 1; PD-L2: Programmed death ligand 2; PK: Pharmacokinetics; S/N: Signal to noise ratio.
\end{abstract}

\section{Acknowledgements}

We would like to thank George Gunn, PhD (GlaxoSmithKline), for his technical review and scientific input and Mita Kuchimanchi (GlaxoSmithKline) for her data analysis support. Medical writing and editorial support, funded by GlaxoSmithKline (Waltham, Massachusetts, USA), and coordinated by Hasan Jamal, MSc, of GlaxoSmithKline, was provided by Shannon Morgan-Pelosi, PhD, and Jennifer Robertson, PhD, of Ashfield MedComms, an Ashfield Health company (Middletown, CT, USA)

\section{Authors' contributions}

All authors provided substantial contributions to the conception or design of the work, or the acquisition, analysis, or interpretation of data for the work. All authors drafted the work, revised it critically for important intellectual content, and provided final approval of the version to be published. All authors had access to full data and analyses presented in this manuscript.

\section{Funding}

Funding for this study was provided by GlaxoSmithKline (NCT02715284).

Trademarks are owned by or licensed to the GlaxoSmithKline group of companies.

\section{Availability of data and materials}

Information on GlaxoSmithKline's data sharing commitments and requesting access to anonymized individual participant data and associated documents can be found at www.clinicalstudydatarequest.com.

\section{Declarations}

\section{Ethics approval and consent to participate}

The human biological samples were sourced ethically, and their research use was in accordance with the terms of the informed consents under an IRB/IEC approved protocol.

\section{Consent for publication}

All authors consent to publication of this manuscript.

\section{Competing interests}

Marilyn Patterson has nothing to disclose.

Lee Anne Beausang has nothing to disclose.

Bonita Rup reports consulting with Tesaro/GlaxoSmithKline on the work described in this manuscript; no compensation was received for the preparation of this manuscript.

Ronald R. Bowsher reports support contracted by Tesaro/GlaxoSmithKline to conduct statistical data analysis for determination of immunogenicity cut points.

Kim Krug reports support contracted by Tesaro/GlaxoSmithKline to conduct statistical data analysis for determination of immunogenicity cut points. 
Murad Melhem is an employee of GlaxoSmithKline.

Sharon Lu is a former employee of GlaxoSmithKline.

\section{Author details}

${ }^{1}$ Analytical Development, Cytiva a Danaher Company, 100 Results Way, MarIborough, MA 01752, USA. ${ }^{2}$ Immunoanalytical Services, Charles River Laboratories, 251 Ballardvale St, Wilmington, MA 01887, USA. ${ }^{3}$ Bonnie Rup Consulting LLC, 234 Washington St, Reading, MA 01867, USA. ${ }^{4}$ CSO, B2S Life Sciences, 97 E Monroe St, Franklin, IN 46131, USA. ${ }^{5}$ Statistics, B2S Life Sciences, 97 E Monroe St, Franklin, IN 46131, USA. ${ }^{6}$ Clinical Pharmacology, Oncology, GlaxoSmithKline, 1000 Winter St, Waltham, MA 02451, USA.

Received: 9 August 2021 Accepted: 17 November 2021

\section{Published online: 20 December 2021}

\section{References}

Bavencio (avelumab) [prescribing information] (2017) https://www.accessdata. fda.gov/drugsatfda_docs/label/2019/761049s006lbl.pdf. Accessed 29 May 2021.

Bloem K, Hernández-Breijo B, Martínez-Feito A, Rispens T (2017) Immunogenicity of therapeutic antibodies: monitoring antidrug antibodies in a clinical context. Ther Drug Monit 39(4):327-332

Bulmer MG (1979) Properties of distributions. In: Principles of statistics. Dover Publications, Inc, New York, pp 61-63

ClinicalTrials.gov (2016) Study of TSR-042, an anti-programmed cell death-1 receptor (PD-1) monoclonal antibody, in participants with advanced solid tumors (GARNET): NCT02715284. https://clinicaltrials.gov/ct2/show/ NCT02715284?term =02715284\&draw $=2 \&$ rank=1. Accessed 6 May 2021

Devanarayan V, Smith WC, Brunelle RL, Seger ME, Krug K, Bowsher RR (2017) Recommendations for systematic statistical computation of immunogenicity cut points. AAPS J 19(5):1487-1498

European Medicines Agency (2017) Guideline on immunogenicity assessment of therapeutic proteins. https://www.ema.europa.eu/en/documents/ scientific-guideline/guideline-immunogenicity-assessment-therapeuticproteins-revision-1_en.pdf. Accessed 23 Feb 2021

European Medicines Agency (2020) JEMPERLI (dostarlimab) [product information] https://www.ema.europa.eu/en/documents/product-information/ jemperli-epar-product-information_en.pdf. Accessed 1 Jun 2021

European Medicines Agency (2021) Jemperli. https://www.ema.europa.eu/en/ medicines/human/EPAR/jemperli. Accessed 24 May 2021

Garcês S, Demengeot J (2018) The immunogenicity of biologic therapies. Curr Probl Dermatol 53:37-48

Gupta S, Richards S, Amaravadi L, Piccoli S, Desilva B, Pillutla R, Stevenson L, Mehta D, Carrasco-Triguero M, Neely R, Partridge M, Staack RF, Zhao X, Gorovits B, Kolaitis G, Sumner G, Stubenrauch KG, Zou L, Amur S, Beaver C, Berger I, Berisha F, Birnboeck H, Bower J, Cho SJ, Cludts I, Cocea L, Donato LD, Fischer S, Fraser S, Garofolo F, Haidar S, Haulenbeek J, Hottenstein C, Hu J, Ishii-Watabe A, Islam R, Jani D, Kadavil J, Kamerud J, Kramer D, Kurki P, MacMannis S, McNally J, Mullan A, Papadimitriou A, PedrasVasconcelos J, Ray S, Safavi A, Saito Y, Savoie N, Fjording MS, Scheibner K, Smeraglia J, Song A, Stouffer B, Tampal N, der Strate BV, Verch T, Welink J, Xu Y, Yang TY, Yengi L, Zeng J, Zhang Y, Zhang Y, Zoog S (2017) 2017 White Paper on recent issues in bioanalysis: a global perspective on immunogenicity guidelines \& biomarker assay performance (Part 3 - LBA: immunogenicity, biomarkers and PK assays). Bioanaylsis 9(24):1967-1996

Imfinzi (durvalumab) [prescribing information] (2017) https://www.accessdata. fda.gov/drugsatfda_docs/label/2020/761069s018lbl.pdf. Accessed 29 May 2021

Jaki T, Allacher P, Horling F (2016) A false sense of security? Can tiered approach be trusted to accurately classify immunogenicity samples? J Pharm Biomed Anal 128:166-173

Jani D, Marsden R, Mikulskis A, Gleason C, Klem T, Krinos Fiorotti C, Myler $H$, Yang L, Fiscella M (2015) Recommendations for the development and validation of confirmatory anti-drug antibody assays. Bioanalysis 7(13):1619-1631

JEMPERLI (dostarlimab) [prescribing information] (2021) https://www.acces sdata.fda.gov/drugsatfda_docs/label/2021/761174s000lbl.pdf. Accessed 1 Jun 2021
Keytruda (pembrolizumab) [prescribing information] (2020) https://www. accessdata.fda.gov/drugsatfda_docs/label/2020/125514s059s064s076s0 83lbl.pdf. Accessed 29 May 2021

Kurki P (2019) Compatibility of immunogenicity guidance by the EMA and the USA FDA. Bioanalysis 11(17):1619-1629

Libtayo (cemiplimab) [prescribing information] (2018) https://www.acces sdata.fda.gov/drugsatfda_docs/label/2019/761097s001lbl.pdf. Accessed 29 May 2021

Lu S, Bowsher RR, Clancy A, Rosen A, Zhang M, Yang Y, Koeck K, Gao M, Potocka E, Guo W, Jen KY, Im E, Milton A (2021) An integrated analysis of dostarlimab immunogenicity. AAPS J 23(5):96

Mire-Sluis AR, Barrett YC, Devanarayan V, Koren E, Liu H, Maia M, Parish T, Scott G, Shankar G, Shores E, Swanson SJ, Taniguchi G, Wierda D, Zuckerman LA (2004) Recommendations for the design and optimization of immunoassays used in the detection of host antibodies against biotechnology products. J Immunol Methods 289(1-2):1-16

Mosteller F, Tukey JW (1977) Robust and resistant measures of location and scale. In: Data analysis and regression: a second course in statistics, 1st edn. Pearson, Reading, pp 206-207

Oaknin A, Tinker AV, Gilbert L, Samouëlian V, Mathews C, Brown J, BarretinaGinesta MP, Moreno V, Gravina A, Abdeddaim C, Banerjee S, Guo W, Danaee H, Im E, Sabatier R (2020) Clinical activity and safety of the antiprogrammed death 1 monoclonal antibody dostarlimab for patients with recurrent or advanced mismatch repair-deficient endometrial cancer: a nonrandomized phase 1 clinical trial. JAMA Oncol 6(11):1766-1772

Opdivo (nivolumab) [prescribing informatoin] (2020) https://www.accessdata. fda.gov/drugsatfda_docs/label/2020/125554s082lbl.pdf.

Pineda C, Hernandez GC, Jacobs IA, Alvarez DF, Carini C (2016) Assessing the immunogenicity of biopharmaceuticals. BioDrugs 30(3):195-206

Shankar G, Devanarayan V, Amaravadi L, Barrett YC, Bowsher R, Finco-Kent D, Fiscella M, Gorovits B, Kirschner S, Moxness M, Parish T, Quarmby V, Smith H, Smith W, Zuckerman LA, Koren E (2008) Recommendations for the validation of immunoassays used for detection of host antibodies against biotechnology products. J Pharm Biomed Anal 48(5):1267-1281

Shapiro SS, Wilk MB (1965) Analysis of variance test for normality (complete samples). Biometrika 52(3-4):591-611

Tecentriq (atezolizumab) [prescribing information] (2016) https://www.acces sdata.fda.gov/drugsatfda_docs/label/2020/761034s027lbl.pdf. Accessed 29 May 2021

US Food and Drug Administration (2019) Immunogenicity testing of therapeutic protein products-developing and validating assays for anti-drug antibody detection. https://www.fda.gov/regulatory-information/searchfda-guidance-documents/immunogenicity-testing-therapeutic-prote in-products-developing-and-validating-assays-anti-drug. Accessed 1 Jun 2021

US Food and Drug Administration (2021) FDA grants accelerated approval to dostarlimab-gxly for dMMR endometrial cancer. https://www.fda.gov/ drugs/drug-approvals-and-databases/fda-grants-accelerated-approvaldostarlimab-gxly-dmmr-endometrial-cancer. Accessed 24 May 2021

van der Neut Kolfschoten M, Schuurman J, Losen M, Bleeker WK, MartínezMartínez P, Vermeulen E, den Bleker TH, Wiegman L, Vink T, Aarden LA, De Baets MH, van de Winkel JG, Aalberse RC, Parren PW (2007) Anti-inflammatory activity of human IgG4 antibodies by dynamic Fab arm exchange. Science 317(5844):1554-1557

Wadhwa M, Knezevic I, Kang HN, Thorpe R (2015) Immunogenicity assessment of biotherapeutic products: an overview of assays and their utility. Biologicals 43(5):298-306

Zoghbi J, Xu Y, Grabert R, Theobald V, Richards S (2015) A breakthrough novel method to resolve the drug and target interference problem in immunogenicity assays. J Immunol Methods 426:62-69

\section{Publisher's Note}

Springer Nature remains neutral with regard to jurisdictional claims in published maps and institutional affiliations. 